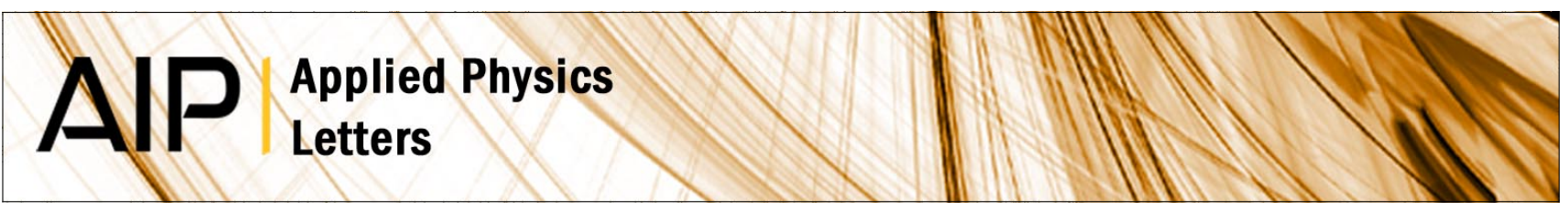

\title{
Three-photon near-infrared quantum splitting in $\beta$-NaYF4:Ho3+
}

D. C. Yu, X. Y. Huang, S. Ye, M. Y. Peng, Q. Y. Zhang et al.

Citation: Appl. Phys. Lett. 99, 161904 (2011); doi: 10.1063/1.3652916

View online: http://dx.doi.org/10.1063/1.3652916

View Table of Contents: http://apl.aip.org/resource/1/APPLAB/v99/i16

Published by the American Institute of Physics.

\section{Related Articles}

Excitonic luminescence in two-dimensionally confined layered sulfide oxides

Appl. Phys. Lett. 101, 191901 (2012)

Effect of $\mathrm{Li}+$ ions on enhancement of near-infrared upconversion emission in $\mathrm{Y} 2 \mathrm{O} 3: \mathrm{Tm} 3+/ \mathrm{Yb} 3+$ nanocrystals J. Appl. Phys. 112, 094701 (2012)

Time-resolved photoluminescence spectroscopy of excitons in layered semiconductor Pbl2 nanoclusters J. Appl. Phys. 112, 093708 (2012)

Photoluminescence under high-electric field of $\mathrm{PbS}$ quantum dots

AIP Advances 2, 042132 (2012)

Bulk silica-based luminescent materials by sol-gel processing of non-conventional precursors

Appl. Phys. Lett. 101, 171908 (2012)

\section{Additional information on Appl. Phys. Lett.}

Journal Homepage: http://apl.aip.org/

Journal Information: http://apl.aip.org/about/about_the_journal

Top downloads: http://apl.aip.org/features/most_downloaded

Information for Authors: http://apl.aip.org/authors

\section{ADVERTISEMENT}
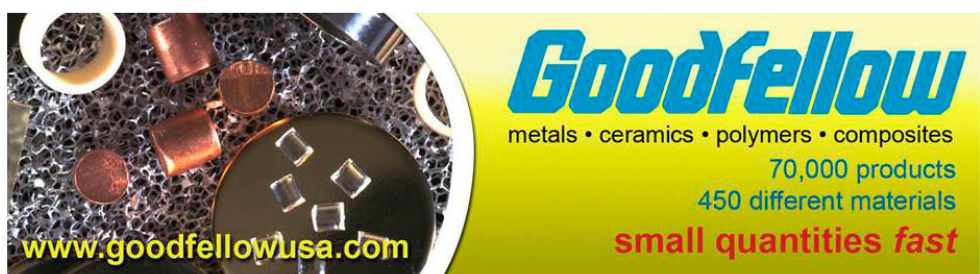


\title{
Three-photon near-infrared quantum splitting in $\beta$ - $\mathrm{NaYF}_{4}: \mathrm{Ho}^{3+}$
}

\author{
D. C. Yu, ${ }^{1}$ X. Y. Huang, ${ }^{1}$ S. Ye,${ }^{1}$ M. Y. Peng, ${ }^{1}$ Q. Y. Zhang, ${ }^{1, a)}$ and L. Wondraczek ${ }^{2}$ \\ ${ }^{1}$ State Key Laboratory of Luminescent Materials and Devices, and Institute of Optical Communication \\ Materials, South China University of Technology, Guangzhou 510641, People's Republic of China \\ ${ }^{2}$ Department of Materials Science, University of Erlangen-Nuremberg, 91058 Erlangen, Germany
}

(Received 7 September 2011; accepted 25 September 2011; published online 18 October 2011)

\begin{abstract}
We report on three-step sequential three-photon near-infrared (NIR) quantum splitting in $\beta$ - $\mathrm{NaYF}_{4}: \mathrm{Ho}^{3+}$, where one absorbed ultraviolet photon is split into three NIR photons with wavelengths 850,1015 , and $1180 \mathrm{~nm}$. The underlying mechanism is analyzed by static and dynamic photoemission and excitation spectroscopy. An internal quantum yield of $124 \%$ is estimated on the basis experimental data and theoretical considerations. Further development of an efficient triply splitting NIR phosphor might open up an approach in achieving efficient photonic devices, which enables more photons emitted than absorbed in the excitation process. (C) 2011 American Institute of Physics. [doi:10.1063/1.3652916]
\end{abstract}

The recent demonstration of efficient visible quantum splitting (QS) in vacuum ultraviolet (VUV)-excited $\mathrm{LiGdF}_{4}: \mathrm{Eu}^{3+}$ represents an exciting step towards the development super-efficient phosphors and luminescent devices. ${ }^{1,2}$ Already, since the first report on QS in the VUV spectral region $\left(\mathrm{Pr}^{3+}\right.$-doped $\mathrm{YF}_{3}$ and $\left.\mathrm{NaYF}_{4}{ }^{3-5}\right)$, intense research activities have been devoted to making use of this effect for potential applications in display and lighting. ${ }^{6-10}$ In a QS process, quantum yield (QY) exceeding unity can be obtained by splitting a photon of relatively high energy into two or more low-energy photons, thus enabling more photons to be emitted than were originally involved in the excitation process. If ultraviolet (UV) or visible photons can be split into two (or more) near-infrared (NIR) photons, this would enable exciting potential for efficient photovoltaic energy conversion. ${ }^{11-13}$ Down-conversion phenomena have hence been studied in numerous materials, particularly, for $\mathrm{Ln}^{3+}-\mathrm{Yb}^{3+}(\mathrm{Ln}=\mathrm{Tb}, \mathrm{Tm}, \mathrm{Pr}, \mathrm{Er}, \mathrm{Nd}$, and $\mathrm{Ho})$ codoping. ${ }^{14-21}$ However, in most of those cases where NIR luminescence originates from $\mathrm{Yb}^{3+}$ through a first-order energy transfer (ET) from $\mathrm{Ln}^{3+}$, QS does actually not occur. Despite the importance of the issue, it appears that there is presently no report on NIR-QS (especially three-photon NIR-QS) in a single-ion activated phosphor. As a consequence, the main mechanisms responsible for NIR-QS not well understood.

Here, we report on the observation of sequential threestep three-photon NIR-QS in $\beta$ - $\mathrm{NaYF}_{4}: \mathrm{Ho}^{3+}$, where a highenergy UV photon splits into three NIR photons with QY greater than unity. On the basis static and dynamic spectroscopic data, we investigate in detail the underlying optoelectronic mechanism.

Powder sample of $\mathrm{NaYF}_{4}$ with a $\mathrm{Ho}^{3+}$-concentration of 1.0 mol. \% was prepared in a hydrothermal procedure, ${ }^{16}$ employing $\mathrm{Y}_{2} \mathrm{O}_{3}, \mathrm{Ho}_{2} \mathrm{O}$ (both $99.99 \%$ ), $\mathrm{HNO}_{3}, \mathrm{NH}_{4} \mathrm{HF}_{2}$, and $\mathrm{NaF}$ (analytical grade) reagents as starting materials. Microstructure of the product was analyzed by powder x-ray diffractometry (XRD, Philips PW1830, $\mathrm{Cu} K \alpha$ ) and scanning electron microscopy (SEM, JEOL JEM-1010). Photolumi-

\footnotetext{
a) Author to whom correspondence should be addressed. Electronic mail: qyzhang@scut.edu.cn.
}

nescence (PL) was studied with a high-resolution spectrophotometer (Edinburgh FLS920) fitted with $450 \mathrm{~W}$ and $\mu \mathrm{F} 900$ microsecond xenon lamps as the excitation sources and by time-correlated single photon counting (employing photomultiplier tubes Hamamatsu R928 and R5509-72).

SEM of the as-prepared product revealed pronounced hexagonal prismatic microrods with an average size of $1 \mu \mathrm{m}$ in diameter and several microns in length. The XRD pattern readily agrees with $\beta-\mathrm{NaYF}_{4}$ (Joint Committee on Powder Diffraction Standards 16-0334) as the sole crystalline phase. Figure 1 shows NIR PL spectra of $\mathrm{NaYF}_{4}: \mathrm{Ho}^{3+}$. Excitation at $287 \mathrm{~nm}$ results in four NIR PL peaks, which are located at $850,965,1015$, and $1180 \mathrm{~nm}$, respectively (Fig. 1(a)). These can be ascribed to the transitions of ${ }^{3} \mathrm{D}_{3} \rightarrow{ }^{3} \mathrm{~K}_{8},{ }^{5} \mathrm{~F}_{2},{ }^{5} \mathrm{~F}_{5} \rightarrow{ }^{5} \mathrm{I}_{7}$, ${ }^{5} \mathrm{~S}_{2},{ }^{5} \mathrm{~F}_{4} \rightarrow{ }^{5} \mathrm{I}_{6}$, and ${ }^{5} \mathrm{I}_{6} \rightarrow{ }^{5} \mathrm{I}_{8}$ of $\mathrm{Ho}^{3+} \cdot{ }^{21,22}$ A further series of characteristic PL bands in the UV-to-visible region can be also detected, corresponding to intra-4f transitions in $\mathrm{Ho}^{3+}{ }^{22}$ inset of Fig. 1(a). The bands at 360 and $850 \mathrm{~nm}$ exhibit almost identical lifetimes (96.2 $\mu$ s and $92.4 \mu \mathrm{s}$, respectively). This observation is taken as evidence for similar electronic origin

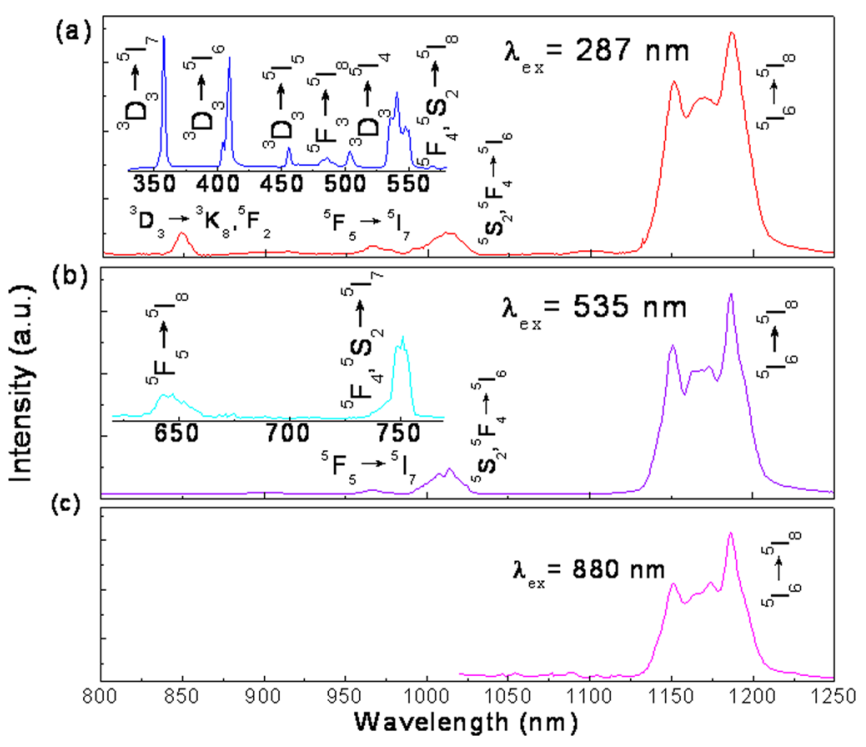

FIG. 1. (Color online) NIR PL spectra of $\mathrm{NaYF}_{4}: 1 \% \mathrm{Ho}^{3+}$ upon excitation of (a) $287 \mathrm{~nm}$, (b) $535 \mathrm{~nm}$, and (c) $880 \mathrm{~nm}$. The insets of Figs. 1(a) and 1(b) show the corresponding visible PL spectra. 
of these two bands, $\mathrm{Ho}^{3+}:{ }^{3} \mathrm{D}_{3} \cdot{ }^{22}$ For a rigorous investigation of the NIR emission scheme, detailed PL spectra (Figs. 1(b) and 1(c)) were recorded for excitation at 535 and $880 \mathrm{~nm}$. Upon $535 \mathrm{~nm}$ excitation, intense NIR emissions peaking at 965, 1015, and $1180 \mathrm{~nm}$ (Fig. 1(b)) could be observed clearly, but the $850 \mathrm{~nm}$ peak is absent for this excitation wavelength. $^{21,22}$ Luminescence occurs in the visible, peaked at $650 \mathrm{~nm}\left({ }^{5} \mathrm{~F}_{5} \rightarrow{ }^{5} \mathrm{I}_{8}\right)$ and $750 \mathrm{~nm}\left({ }^{5} \mathrm{~S}_{2},{ }^{5} \mathrm{~F}_{4} \rightarrow{ }^{5} \mathrm{I}_{7}\right)$, shown in the inset of Fig. 1(b). For $880 \mathrm{~nm}$ excitation, however, only the NIR PL peak at $1180 \mathrm{~nm}$ could be detected, originating from ${ }^{5} \mathrm{I}_{6} \rightarrow{ }^{5} \mathrm{I}_{8}$ in $\mathrm{Ho}^{3+}$ (Fig. 1(c)).

In Fig. 2, PL excitation (PLE) spectra of $\mathrm{NaYF}_{4}: 1 \% \mathrm{Ho}^{3+}$ is shown for the wavelength range of $250-670 \mathrm{~nm}$. The pronounced, overlapped PLE bands at 275 and $287 \mathrm{~nm}$ correspond to the transitions of ${ }^{5} \mathrm{I}_{8} \rightarrow{ }^{3} \mathrm{P}_{0}$ and ${ }^{5} \mathrm{I}_{8} \rightarrow{ }^{3} \mathrm{G}_{3},{ }^{3} \mathrm{~L}_{8},{ }^{22}$ respectively. These two bands are the only ones visible when monitoring emission at $410 \mathrm{~nm}\left({ }^{3} \mathrm{D}_{3} \rightarrow{ }^{5} \mathrm{I}_{6}\right)$ and $850 \mathrm{~nm}$, respectively, while for other emission bands, a variety of further excitation peaks can be detected (obviously related to intra-4f transitions from the ${ }^{5} \mathrm{I}_{8}$ ground state to the corresponding intermediate states, ${ }^{21,22}$ ). This may confirm that the $850 \mathrm{~nm}$ NIR emission band only appears when exciting the ${ }^{3} \mathrm{P}_{0}$ and ${ }^{3} \mathrm{G}_{3},{ }^{3} \mathrm{~L}_{8}$ states. Comparing the individual PLE spectra to each other, no PLE band occurs at $640 \mathrm{~nm}\left({ }^{5} \mathrm{I}_{8} \rightarrow{ }^{5} \mathrm{~F}_{5}\right)$ when monitoring the $1015 \mathrm{~nm}$ emission. This further indicates that only the states of ${ }^{5} \mathrm{~S}_{2},{ }^{5} \mathrm{~F}_{4}$, and above yield NIR $1015 \mathrm{~nm}$ emission. ${ }^{21}$ At this point, it may already be speculated that for high-energy excitation (that is, at $287 \mathrm{~nm}$ ), the simultaneous appearance of the 850,1015 , and $1180 \mathrm{~nm}$ emission bands originates from "cascade" radiative transitions through several intermediate levels in $\mathrm{Ho}^{3+3-5}$

The schematic energy-level diagram of $\mathrm{Ho}^{3+}$ shown in Fig. 3 illustrates the sequential three-step three-photon NIRQS process. Upon excitation of the $287 \mathrm{~nm}$ light, the ${ }^{3} \mathrm{D}_{3}$ state of $\mathrm{Ho}^{3+}$ populated by fast multiphonon relaxation can emit efficiently the first $850 \mathrm{~nm}$ NIR photon through the ${ }^{3} \mathrm{D}_{3} \rightarrow{ }^{3} \mathrm{~K}_{8},{ }^{5} \mathrm{~F}_{2}$ transition (step 1). On the basis of the energy gap law $^{23}$ and the intense visible emission bands shown in the inset of Fig. 1(a), the excited ${ }^{3} \mathrm{D}_{3}$ state is proven to be the long-lived level because of the large energy gap of

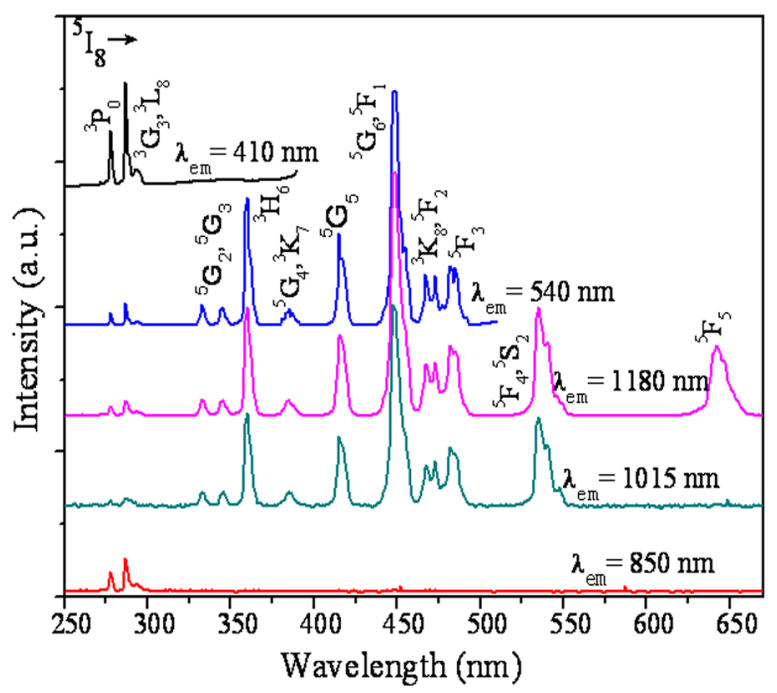

FIG. 2. (Color online) PLE spectra monitored at various PL wavelengths of $\mathrm{NaYF}_{4}: 1 \% \mathrm{Ho}^{3+}$ phosphor.

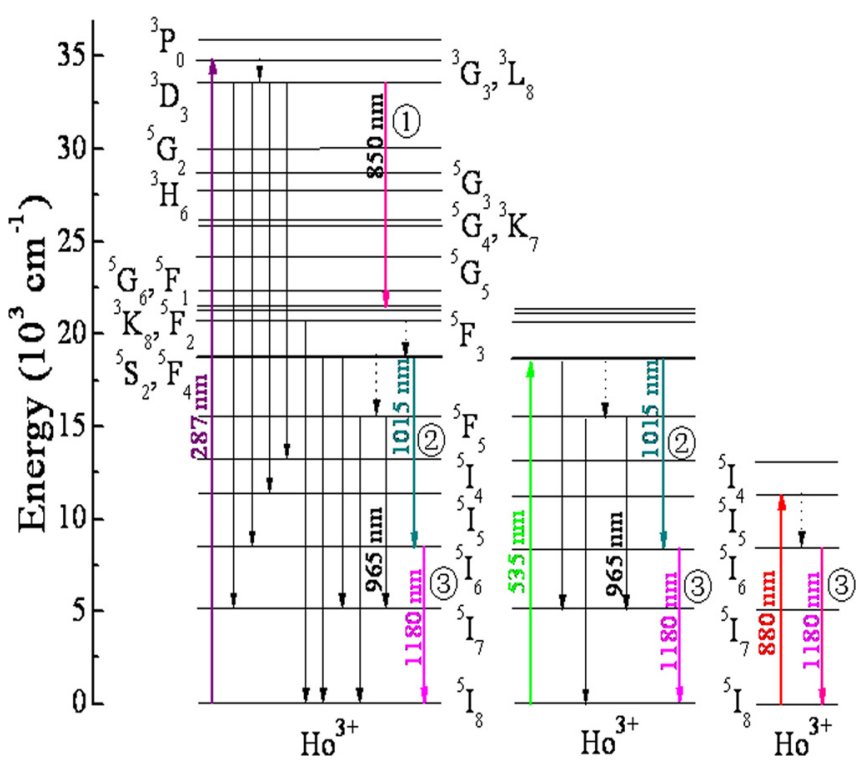

FIG. 3. (Color online) Schematic energy-level diagram of $\mathrm{Ho}^{3+}$ showing the concept of sequential three-step NIR-QS under excitation of 287, 535, and $808 \mathrm{~nm}$, respectively. (1) the first step, ${ }^{3} \mathrm{D}_{3} \rightarrow{ }^{3} \mathrm{~K}_{8},{ }^{5} \mathrm{~F}_{2}$ at $850 \mathrm{~nm}$; (2) the second step, ${ }^{5} \mathrm{~S}_{2},{ }^{5} \mathrm{~F}_{4} \rightarrow{ }^{5} \mathrm{I}_{6}$ at $1015 \mathrm{~nm}$; and (3) the third step, ${ }^{5} \mathrm{I}_{6} \rightarrow{ }^{5} \mathrm{I}_{8}$ at $1180 \mathrm{~nm}$. Solid arrow represents optical transition, and short-dotted arrow is NR process.

${ }^{3} \mathrm{D}_{3} \rightarrow{ }^{5} \mathrm{G}_{2} \quad\left(\sim 2800 \mathrm{~cm}^{-1}\right)$ but small maximum phonon energy of $\mathrm{NaYF}_{4}$ host lattice $\left(\sim 400 \mathrm{~cm}^{-1}\right) .{ }^{24}$ Following the ${ }^{5} \mathrm{~S}_{2},{ }^{5} \mathrm{~F}_{4}$ states populated by phonon-assisted nonradiative relaxation (NR) from the excited ${ }^{3} \mathrm{~K}_{8},{ }^{5} \mathrm{~F}_{2}$ states, relaxation to ${ }^{5} \mathrm{I}_{6}$ occurs radiatively by emission of a second $1015 \mathrm{~nm}$ photon (step 2). Finally, ${ }^{5} \mathrm{I}_{6}$ relaxes by emission of a third photon with a wavelength of $1180 \mathrm{~nm}$ (step 3), completing a process of three-photon NIR-QS. The typical energy gaps of around 2900 and $3500 \mathrm{~cm}^{-1}$ enable radiative decay to dominate over multiphonon relaxation of ${ }^{5} \mathrm{~S}_{2},{ }^{5} \mathrm{~F}_{4}$, and ${ }^{5} \mathrm{I}_{6}$ states. Hence, these levels serve as intermediate levels of the QS process. ${ }^{23}$ In contrast, if ${ }^{5} \mathrm{~S}_{2},{ }^{5} \mathrm{~F}_{4}$ states are directly excited at $535 \mathrm{~nm}$, the sequential two-step transitions of 2 and 3 occur, where ${ }^{5} \mathrm{I}_{6}$ acts as intermediate level. Completing this picture, only step 3 is detected for direct excitation to ${ }^{5} \mathrm{I}_{5}$ state excited by $880 \mathrm{~nm}$ (Fig. 3).

Figure 4(a) shows time resolved emission spectra of $\mathrm{NaYF}_{4}: 1 \% \mathrm{Ho}^{3+}$, excited at $287 \mathrm{~nm}$ with a pulsed source. It can be seen that the bands at 360 and $410 \mathrm{~nm}$ dominate initially (at delay time of $59.5 \mu \mathrm{s}$ ). As already noted, they correspond to the transitions of ${ }^{3} \mathrm{D}_{3} \rightarrow{ }^{5} \mathrm{I}_{7}$ and ${ }^{3} \mathrm{D}_{3} \rightarrow{ }^{5} \mathrm{I}_{6}$ of $\mathrm{Ho}^{3+}$ and, hence, appear after sufficient population of the ${ }^{3} \mathrm{D}_{3}$ level via NR from the excited ${ }^{3} \mathrm{G}_{3},{ }^{3} \mathrm{~L}_{8}$ states. The $485 \mathrm{~nm}$ emission band $\left({ }^{5} \mathrm{~F}_{3} \rightarrow{ }^{5} \mathrm{I}_{8}\right)$ emerges after a delay time of $60.5 \mu$ s and the band at $540 \mathrm{~nm}\left({ }^{5} \mathrm{~S}_{2},{ }^{5} \mathrm{~F}_{4} \rightarrow{ }^{5} \mathrm{I}_{8}\right)$ grows in clearly after $70.0 \mu \mathrm{s}$. The latter then increases dramatically relative to the intensity of all other emission bands related to the ${ }^{3} \mathrm{D}_{3}$ state. These dynamic processes of ET indicate that the excited ${ }^{3} \mathrm{D}_{3}$ state might be faster depopulated to the ${ }^{3} \mathrm{~K}_{8},{ }^{5} \mathrm{~F}_{2}$ states through a one-step NIR transition of ${ }^{3} \mathrm{D}_{3} \rightarrow{ }^{3} \mathrm{~K}_{8},{ }^{5} \mathrm{~F}_{2}$ (step 1 , $850 \mathrm{~nm}$ ) rather than via stepwise NR decay. As the delay time increases, densely populated ${ }^{3} \mathrm{~K}_{8},{ }^{5} \mathrm{~F}_{2}$ states relax nonradiatively to the following ${ }^{5} \mathrm{~F}_{3}$ state, which then decays either to the ${ }^{5} \mathrm{I}_{8}$ ground state by emitting a $485 \mathrm{~nm}$ photon or depopulates non-radiatively to ${ }^{5} \mathrm{~S}_{2},{ }^{5} \mathrm{~F}_{4}$ due to the small energy gap between those states $\left(\sim 1800 \mathrm{~cm}^{-1}\right)$. The excited ${ }^{5} \mathrm{~S}_{2},{ }^{5} \mathrm{~F}_{4}$ states 


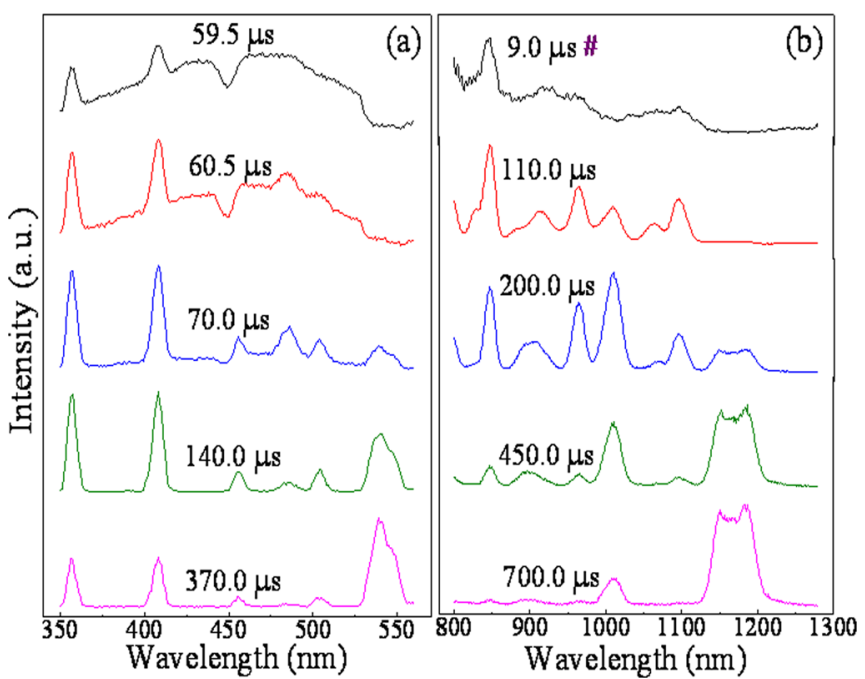

FIG. 4. (Color online) Visible (a) and NIR (b) time resolved emission spectra excited at $287 \mathrm{~nm}$ with a $\mu \mathrm{F} 900$ microsecond xenon lamp; \# refers to that recorded in a fine time interval of $0.2 \mu \mathrm{s}$.

then would sequentially emit the second $1015 \mathrm{~nm}$ NIR photon (2) and the third $1180 \mathrm{~nm}$ NIR photon (3).

A second set of delay spectra is shown in Fig. 4(b) for $287 \mathrm{~nm}$ pulsed excitation. In the early stage of relaxation (delay time of $9.0 \mu \mathrm{s}$ ), only the $850 \mathrm{~nm}$ NIR PL band can be detected, corresponding to ${ }^{3} \mathrm{D}_{3} \rightarrow{ }^{3} \mathrm{~K}_{8},{ }^{5} \mathrm{~F}_{2}$ transition (step 1). Subsequently, after $110.0 \mu \mathrm{s}$, the $1015 \mathrm{~nm}$ band $\left({ }^{5} \mathrm{~S}_{2},{ }^{5} \mathrm{~F}_{4} \rightarrow\right.$ ${ }^{5} \mathrm{I}_{6}$, step 2) and the $965 \mathrm{~nm}$ emission band $\left({ }^{5} \mathrm{~F}_{5} \rightarrow{ }^{5} \mathrm{I}_{7}\right)$ can be observed. The final band of ${ }^{5} \mathrm{I}_{6} \rightarrow{ }^{5} \mathrm{I}_{8}$ at $1180 \mathrm{~nm}$ (step 3) occurs after a delay time of $200.0 \mu$ s and increases in intensity with progressing delay. These results provide further direct evidence for the assumed sequential three-step NIRQS in $\mathrm{Ho}^{3+}$, with the ${ }^{3} \mathrm{~K}_{8},{ }^{5} \mathrm{~F}_{2}$, and ${ }^{5} \mathrm{I}_{6}$ states serving as intermediate levels.

Total QY $\left(\eta_{Q Y}\right)$ of $\mathrm{NaYF}_{4}: \mathrm{Ho}^{3+}$ can be estimated from the PL spectrum $\left(\lambda_{\mathrm{ex}}=287 \mathrm{~nm}\right)$. Thereby, $\eta_{Q Y}$ is defined as the number of photons re-emitted per number of absorbed UV photons. Hence, visible QY $\left(\eta_{V I S}\right)$ and NIR QY $\left(\eta_{N I R}\right)$ may be distinguished NIR-QS. ${ }^{14-21}$ The integral fluorescence intensities of all visible PL bands were calculated. By taking into account, the emission mechanism (Fig. 3), $\eta_{Q Y}$ can be appropriately estimated as follows: ${ }^{11,12}$

$$
\begin{aligned}
\eta_{Q Y}= & \eta_{V I S}+\eta_{N I R} \\
= & \beta^{3} D_{3} \rightarrow{ }^{5} I_{7}+2 \sum_{J=4,5,6} \beta^{{ }^{3} D_{3} \rightarrow{ }^{5} I_{J}}+\beta^{5} F_{3} \rightarrow{ }^{5} I_{8} \\
& +\eta_{Q Y}^{*}\left(\sum_{J=7,8} \beta_{{ }^{5} S_{2},{ }^{5} F_{4} \rightarrow{ }^{5} I_{J}}+\beta_{5 F_{5} \rightarrow{ }^{5} I_{8}}\right),
\end{aligned}
$$

where $\beta_{\exp }$ are the luminescence branching ratios measured in our experiment. Using the Judd-Ofelt parameters of $\mathrm{LiYF}_{4}: \mathrm{Ho}^{3+}$ single crystal $\left(\Omega_{2}=1.03 \times 10^{-20} \mathrm{~cm}^{2}, \Omega_{4}\right.$ $\left.=2.32 \times 10^{-20} \mathrm{~cm}^{2}, \Omega_{6}=1.93 \times 10^{-20} \mathrm{~cm}^{2}\right),{ }^{24}$ the total QY of ${ }^{5} \mathrm{~S}_{2},{ }^{5} \mathrm{~F}_{4}$ states, $\eta_{Q Y}^{*}$, can be rationally evaluated from ${ }^{12}$

$$
\eta_{Q Y}^{*}=\eta_{5 F_{4},{ }^{5} S_{2}}+\left(\beta_{5 F_{4},{ }^{5} S_{2} \rightarrow{ }^{5} F_{5}}^{*}+\sum_{J=4,5,6} \beta_{5 F_{4},{ }^{5} S_{2} \rightarrow{ }^{5} I_{J}}^{*}\right) \eta_{5} F_{4},{ }^{5} S_{2} \eta_{5},
$$

where QY for the ${ }^{5} \mathrm{~F}_{4},{ }^{5} \mathrm{~S}_{2}\left({ }^{5} \mathrm{I}_{6}\right)$ states, $\eta^{5} F_{4}{ }^{5} S 2\left(\eta^{5} I 6\right)$, is set to unity, neglecting NR processes, and $\beta^{*}=A_{J} / \sum_{i} A_{J i}$ ( $A$ is the radiative transition rates) refers to the relative intensities of transitions from the excited levels $\left({ }^{5} \mathrm{~F}_{4},{ }^{5} \mathrm{~S}_{2}\right)$ to all terminal levels. The reduced matrix elements were adopted from Ref. 24, the refractive index of $\mathrm{NaYF}_{4}$ is $1.486 .{ }^{25}$ Accordingly, $\eta_{Q Y}^{*}$ of $\sim 110 \%$ is obtained, resulting in $\eta_{Q Y}$ of about $124 \%$ for the three-step NIR-QS in $\mathrm{Ho}^{3+}$. Here, the approximate value of $\eta_{Q Y}$ would represent just the lower end of the expected real value of total $\mathrm{QY}$ because $\mathrm{QY}$ of the ${ }^{3} \mathrm{D}_{3} \rightarrow{ }^{3} \mathrm{~K}_{8},{ }^{5} \mathrm{~F}_{2}$ transition is completely neglected by assuming that the ${ }^{5} \mathrm{~S}_{2},{ }^{5} \mathrm{~F}_{4}$ states only populate by fast NR from the excited ${ }^{3} \mathrm{D}_{3}$.

In summary, a sequential three-step three-photon NIRQS has been demonstrated in $\mathrm{Ho}^{3+}$ doped $\beta-\mathrm{NaYF}_{4}$. Upon excitation with a UV photon, cascadic emission of three NIR photons at 850,1015 , and $1180 \mathrm{~nm}$ occurs. The electronic states of ${ }^{3} \mathrm{~K}_{8},{ }^{5} \mathrm{~F}_{2}$, and ${ }^{5} \mathrm{I}_{6}$ in $\mathrm{Ho}^{3+}$ act as intermediate levels. Theoretical estimation indicates a total QY of about $124 \%$. It is believed that the low phonon energy of $\mathrm{NaYF}_{4}$ of $\sim 400 \mathrm{~cm}^{-1}$ is a key prerequisite for the sequential three-step three-photon NIR-QS in $\mathrm{Ho}^{3+}$. As such, the concept of triply splitting NIR-QS may offer an interesting route towards the design of efficient photonic devices.

Financial support from National Science Foundation of China (50872036 and U0934001) and Chinese Ministry of Education (20100172110012) is gratefully acknowledged.

${ }^{1}$ R. T. Wegh, H. Donker, K. D. Oskam, and A. Meijerink, Science 282, 663 (1999).

${ }^{2}$ R. T. Wegh, E. V. D. Van Loef, and A. Meijerink, J. Lumin. 90, 111 (2000). ${ }^{3}$ J. L. Sommerdijk, A. Bril, and A. W. de Jager, J. Lumin. 8, 341 (1974).

${ }^{4}$ W. W. Piper, J. A. de Luca, and F. D. Ham, J. Lumin. 8, 344 (1974).

${ }^{5}$ R. Pappalardo, J. Lumin. 14, 159 (1976).

${ }^{6}$ C. Feldmann, T. Juster, C. R. Ronda, and P. J. Schmidt, Adv. Funct. Mater. 13, 511 (2003).

${ }^{7}$ S. Shionoya and W. M. Yen, Phosphor Handbook (CRC, Boca Raton, FL, 1998), Vol. 3, p. 623.

${ }^{8}$ N. Kodama and Y. Watanabe, Appl. Phys. Lett. 84, 4141 (2004).

${ }^{9}$ T. J. Lee, L. Y. Luo, W. G. Diau, T. M. Chen, B. M. Cheng, and C. Y. Tung, Appl. Phys. Lett. 89, 131121 (2006).

${ }^{10}$ S. M. Loureiro, A. Setlur, W. Heward, S. T. Taylor, H. Comanzo, P. Schmidt, and U. Happek, Chem. Mater. 17, 3108 (2005).

${ }^{11}$ Q. Y. Zhang and X. Y. Huang, Prog. Mater. Sci. 55, 353 (2010).

${ }^{12}$ B. M. van der Ende, L. Aarts, and A. Meijerink, Phys. Chem. Chem. Phys. 11, 11081 (2009).

${ }^{13}$ B. S. Richards, Sol. Energy Mater. Sol. Cells 90, 1189 (2006).

${ }^{14}$ P. Vergeer, T. J. H. Vlugt, M. H. F. Kox, M. I. Den Hertog, J. P. J. M. van der Eerden, and A. Meijerink, Phys. Rev. B 71, 014119 (2005).

${ }^{15}$ Q. Y. Zhang, C. H. Yang, and Y. X. Pan, Appl. Phys. Lett. 90, 021107 (2007).

${ }^{16}$ X. P. Chen, W. J. Zhang, and Q. Y. Zhang, Physica B 406, 1248 (2011).

${ }^{17}$ B. M. van der Ende, L. Aarts, and A. Meijerink, Adv. Mater. 21, 3073 (2009).

${ }^{18}$ D. Q. Chen, Y. S. Wang, Y. L. Yu, P. Huang, and F. Y. Weng, Opt. Lett. 33, 1884 (2008).

${ }^{19}$ J. J. Eilers, D. Biner, J. T. Van Wijngaaerden, K. Krämer, H.-U. Güdel, and A. Meijerink, Appl. Phys. Lett. 96, 151106 (2010).

${ }^{20}$ J. M. Meijer, L. Aarts, B. M. van der Ende, T. J. H. Vlugt, and A. Meijerink, Phys. Rev. B 81, 035107 (2010).

${ }^{21}$ H. Lin, D. Q. Chen, Y. L. Yu, A. P. Yang, and Y. S. Wang, Opt. Lett. 36, 876 (2011).

${ }^{22}$ M. Malinowski, Z. Frukacz, M. Szuflińska, A. Wnuk, and M. Kaczkan, J. Alloys. Compd. 300-301, 389 (2000).

${ }^{23}$ J. M. F. van Dijk and M. F. H. Schuurmans, J. Chem. Phys. 78, 5317 (1983).

${ }^{24}$ B. M. Walsh, N. P. Barnes, and B. Di Bartolo, J. Appl. Phys. 83, 2772 (1998).

${ }^{25}$ D. Knowles, A. Cassanho, H. P. Jenssen, in Tunable Solid State Laser, edited by L. D. Buggor, L. Esterowitz, and L. G. DeShazer (Springer, Berlin, 1989), pp. 139-145. 